\title{
Policy Deliberation and Voter Persuasion: Experimental Evidence from an Election in the Philippines 0
}

\author{
Gabriel López-Moctezuma California Institute of Technology \\ Leonard Wantchekon Princeton University and African School of Economics \\ Daniel Rubenson Ryerson University \& Research Institute of Industrial Economics \\ Thomas Fujiwara Princeton University, NBER, and CIFAR \\ Cecilia Pe Lero University of São Paulo
}

\begin{abstract}
In a randomized experiment in cooperation with two national parties competing in a congressional election in the Philippines, we estimate the causal effect on voting behavior of a town-hall style campaign in which candidates discuss their campaign platform with small groups of citizens. Keeping the parties' platform fixed, we find that town-hall meetings have a positive effect on parties' vote shares compared to the status quo, in which voters play a passive role. Consistent with the parties' advocacy for underprivileged groups, we observe heterogeneous effects by income, education, and gender. Deliberative campaigns increase voters' awareness on the issues parties campaign on, affecting the vote of the direct beneficiaries of the parties' platform.

Verification Materials: The data and materials required to verify the computational reproducibility of the results, procedures, and analyses in this article are available on the American Journal of Political Science Dataverse within the Harvard Dataverse Network, at: https://doi.org/10.7910/DVN/S3HACJ.
\end{abstract}

\section{Introduction}

$\mathrm{N}$ ormative proponents of a participatory approach to political decision making suggest that deliberation can lead to revelatory discussion and the resolution of political conflicts (Gutmann and Thompson 1996; Habermas 1996; Macedo 2010). On purely instrumental grounds, deliberation may be an avenue through which individuals can share private information prior to collective decision making, helping voters to implement more informed choices. (AustenSmith and Feddersen 2006; Coughlan 2000; Meirowitz
2006). Moreover, the opportunity to discuss relevant issues might provide citizens the motivation to actively become more informed about policy and act on this information (Esterling, Neblo, and Lazer 2011). In fact, laboratory and observational evidence has shown that policy choices can be more effective in changing attitudes, eliciting information, and encouraging cooperation when they are chosen through deliberative settings (Ban, Jha, and Rao 2012; Barabas 2004; Dal Bó, Foster, and Putterman 2010; Goeree and Yariv 2011; Karpowitz and Mendelberg 2014).

In principle, if deliberative forums can increase citizens' incentives to become more informed and affect

Gabriel Lopez-Moctezuma is Assistant Professor of Political Science, Humanities and Social Sciences Division, Baxter Hall, Room 105, California Institute of Technology, Pasadena, CA 91125 (glmoctezuma@caltech.edu). Leonard Wantchekon is Professor of Politics and International Affairs, Princeton University, Bendheim Hall, Room 321, Princeton, NJ 08544 (lwantche@princeton.edu). Daniel Rubenson is Professor of Politics, Ryerson University, 350 Victoria Street, Toronto ON, Canada M5B 2K3 (rubenson@ryerson.ca). Thomas Fujiwara is Associate Professor of Economics, Princeton University, Julis Romo Building, Room 131, Princeton, NJ 08544 (fujiwara@princeton.edu). Cecilia Pe Lero is a postdoctoral fellow at the Centro de Estudos de Metrópole (CEM) based at the University of São Paulo, Avenida Professor Luciano Gualberto, 315, São Paulo, Brazil 05508-900 (cecilia.lero@gmail.com).

We thank Scott Abramson, Chris Blattman, Don Green, Macartan Humphreys, Amaney Jamal, Massimo Morelli, Betsy Paluck, Cyrus Samii, and seminar participants at Columbia University, Princeton University, the World Bank, and Yale University for useful comments on earlier versions of this article. Financial support from The Mamdouha S. Bobst Center for Peace and Justice is gratefully acknowledged. 
their political behavior, it might be in the interest of politicians to use them as an electoral strategy to persuade voters of the merits of a desired alternative, offering a bridge between the practice of deliberative democracy and the domain of electoral politics.

Empirically, assessing the potential benefits of implementing deliberative forums on a politician's electoral prospects is challenging, as these could be confounded with other factors that might affect behaviors of both politicians and citizens. In general, the effect that any political strategy might have on voting behavior is a function of the platform message, the communication strategy, the intrinsic traits of the politician, and the audience characteristics. Therefore, being able to disentangle whether and to what extent deliberation affects voting behavior requires manipulating the communication strategy of the campaign, while keeping fixed any other relevant variable that might affect voting behavior. In this study, we implement such an experimental design by randomizing the assignment of town-hall meetings to different areas, while keeping campaign platforms fixed.

The implementation of the experiment involved the cooperation of two national party lists competing for representation in the legislative election of May 2013 in the Philippines. Importantly, the two party lists with which we collaborated claimed to represent and advocate for distinct societal groups-namely women in one platform and the urban poor in another-emphasizing distinct legislative policies favorable to each of these groups in their campaign platforms. This allows us to measure the impact of town-hall meetings on the subset of voters who are more susceptible to the information contained in the campaign messages. Moreover, the Filipino partylist contest is ideal to assess the effect of deliberative forums on electoral returns, as it permits us to focus on a type of party that distinguishes itself programmatically from the mainstream political organizations that compete in other legislative, presidential, and local mayoral elections, where clientelistic practices, corruption, and vote buying have been widespread in the recent past (e.g., Hicken et al. 2014). ${ }^{1}$

The treatment we implement manipulates the communication strategy for each party-list platform. First, we design a deliberative campaign in which the partylist message was communicated in town-hall meetings, where voters and party representatives discussed and debated the party-list platform and its potential ben-

${ }^{1}$ According to law, $20 \%$ of congressional seats are reserved for minority groups. To fill these seats, voters choose from a set of "party lists" in a closed-list, proportional representation system. efits. The communication strategy in control villages was the "business-as-usual" campaign that parties implemented elsewhere. The same policy platform discussed in town-hall meetings was also delivered through "oneway" communication technologies, such as the distribution of party propaganda and speeches in party rallies, with no direct participation of voters or debate between party representatives and citizens.

In the control group, we explicitly did not introduce any restriction on the communication strategy of party lists except that town-hall meetings were not implemented. ${ }^{2}$ In this way, we ensure that our results are not driven by an artificial condition imposed on politicians that could differ greatly from the way they would usually campaign.

Second, party lists were randomly assigned to different areas and a treatment subset of these areas sets up two or three town-hall meetings with around 40 participants each. This random assignment allowed us to control for the effect that intrinsic party characteristics might have had on voting behavior. We do this by focusing only on the electoral prospects of a given party list in treatment versus control areas.

Given the random assignment of a deliberative campaign strategy, we examine whether the presence of town-hall meetings, in which citizens are encouraged to deliberate with candidates about policy, affects voters' attitudes and political behavior differently from the "business-as-usual" campaign.

We argue that the favorable conditions to engage with both politicians and other citizens in town-hall meetings can improve voters' knowledge about the private benefits and externalities of programmatic policies advocated by different candidates. This information in turn, might generate a benchmark or focal point to evaluate politicians. The increase in voters' awareness about the candidate's policies and its consequences on different societal groups might translate into an increase in votes from those citizens whose most preferred policy is closer to the party's platform.

Our main results show that town-hall meetings have a positive effect on both official and self-reported measures of electoral support. Conditioning on casting a vote, party lists increased their official vote shares around $46 \%$ with respect to the control group in those areas assigned to the deliberative campaign. In this context, we do not find that holding town-hall meetings increases

${ }^{2}$ It is important to note here that deliberative campaigns, as the ones we designed for this experiment, were not part of the campaign strategy of any of the involved party lists, either in past elections or prior to their agreement to cooperate with the experiment. 
turnout, as other campaign strategies, such as face-toface voter mobilization, appear to do (Gerber and Green 2000; Green, Gerber, and Nickerson 2003). This is not surprising, however, as we measure turnout as casting a valid vote in the party-list election, which occurs concurrently with the election to other offices (e.g., House, senatorial, mayoral, and provincial elections). To the extent these other races are the main forces driving voters to the polls, no effects on party-list turnout would be expected.

When we analyze potential heterogeneous effects of town-hall meetings by party list and sociodemographic characteristics using a postelection survey, we find positive and significant electoral returns of town-hall meetings only for women when the party list that is campaigning is the one running a feminist platform (i.e., Akbayan party). Similarly, we find a positive and significant effect of the implementation of town-hall meetings only on poor and less educated voters when the party list that is campaigning is the one running the pro-poor platform (i.e., Umalab Ka party).

Along with the impact on voting behavior, we find a widespread attitudinal change on the issues at the center of the party-list platforms when they are delivered via deliberation. On the one hand, voters exposed to the pro-feminist platform in town-hall meetings increased their disagreement with gender discrimination and sexism by 0.43 standard deviation (s.d.) units with respect to the control group. On the other hand, voters exposed to the pro-poor platform were 0.13 s.d. units more concerned about poverty-related issues when town-hall meetings were in place compared to "business-as-usual" campaigns.

These results confirm that deliberative campaigns are indeed an effective way of delivering a campaign message and affect voters' attitudes toward relevant policy issues. More importantly, the heightened knowledge and awareness of policy proposals in town-hall meetings has relevant consequences on citizen's voting behavior, specifically persuading those voters who would directly benefit from the party's platform to cast a vote in their favor.

Our analysis follows a burgeoning empirical literature using randomized field experiments in actual campaigns with the collaboration of politicians. Our article is closely related to Fujiwara and Wantchekon (2013) who find that programmatic platforms delivered through a deliberative campaign reduce the perception of clientelism and increase electoral returns. Although this article makes a contribution on the relevance of platform transparency, it is unable to isolate the effect of deliberation from that of the platform content itself, as the latter also changes by treatment status. ${ }^{3}$ In contrast, our experiment focuses on an electoral race where parties can only vote on legislation in Congress and do not hold discretionary power to offer any type of particularistic spending. Thus, the legislative platform offered by parties' representatives remains fixed in both treatment and control areas, allowing us to isolate the effect of deliberative campaigns.

In the context of US congressional elections, Esterling, Neblo, and Lazer (2011) design a deliberative field experiment and show that participating in a deliberating session with politicians motivate constituents to become more informed about policy-relevant issues. In Nigeria, Collier and Vicente (2014) show experimental evidence that the implementation of a campaign against electoral violence through the holding of town meetings decreases violence perception in local elections, improve citizen empowerment, and increase voter turnout. Casey, Glennester, and Bidwell (2015) find a positive impact of voters' exposure to candidates' debates on voting behavior, campaign spending, and politicians' performance using a field experiment in Sierra Leone.

Finally, our article is related to the works of Kendall, Nannicini, and Trebbi (2015) and Dewan, Humphreys, and Rubenson (2014) that experimentally assess the effects of different informational campaign treatments on voting behavior. Unlike our article, their messages did not involve a deliberative setting. Instead, they manipulated the content of the messages themselves, making them either about the candidate's valence or ideology.

\section{Party-List Electoral System}

Since the reinstatement of electoral democracy in 1986, the Philippines' political system has been formally composed of a presidential executive and a bicameral legislative body. The Senate is composed of 24 members elected every six years, whereas the House of Representatives is composed of 292 members elected every three years. A new constitution was drafted in 1987 that reapportioned congressional districts, reduced the term lengths for members of the House of Representatives, and introduced term limits for all elected officials. In addition, and with the intention of strengthening the party system, advancing programmatic-based parties, and reducing the elite monopoly of political power, the 1987

\footnotetext{
${ }^{3}$ Under deliberation, candidates and voters debated about a universalistic platform that emphasized the national benefits of policies, whereas under the "business-as-usual" campaign, candidates offered a mix of clientelistic goods (cash distribution, patronage, and discretionary spending), as well as universalistic policies.
} 
Constitution mandated that $20 \%$ of the lower House should be composed of representatives of marginalized societal groups such as "labor, peasant, fisherfolk, urban poor, indigenous cultural communities, elderly, handicapped, women, youth, veterans, overseas workers, professionals, and other such sectors as may be provided by law, except the religious sector" (Article VI; Section 5.2). ${ }^{4}$ However, it was not until 1995 that this mandate was implemented via the Party-List System Act, which stated that "the State shall promote proportional representation in the election of representatives to the House of Representatives through a party-list system. . which will enable Filipino citizens belonging to the marginalized and underrepresented sectors... to become members of the House of Representatives" (Section 2). In practice, partylist seats in Congress are allocated via a closed-list proportional representation election at the national level. The Philippines' Commission of Elections (COMELEC) is in charge of certifying whether a political organization that seeks party-list status is organized along one of the above-mentioned sectoral groups. As a prerequisite, a political organization needs to submit an ordered list of at least five candidates who need to be registered voters older than 25 years, and bona fide members of the organization nominating them. Party-list candidates cannot be nominated by more than one party or run for other elective offices in the same election. In addition, those candidates who lost a race in the immediate preceding election cannot run under the party-list system. Beyond these requirements, there are no formal quotas by category of disadvantaged group and any legislative seat allocated to the party-list system can be occupied by any of these political organizations.

For the party-list election, a voter chooses one party via closed list and each party that receives $2 \%$ of the party-list vote at the national level is entitled to one seat and an additional seat for every $2 \%$ thereafter, for a maximum of three seats per party list. Therefore, every three years at each election, voters cast two votes for the House of Representatives, one for their district representative via plurality rule and one for a national party list.

\section{Experimental Design}

The campaign experiment we analyze here focuses on the party-list election that took place on May 13, 2013. In this election, 58 of 289 Congress seats were allocated

${ }^{4}$ The remaining $80 \%$ of seats are allocated by simple majority from single-member districts apportioned among the Philippines' provinces and cities. for party-list representatives among more than 130 registered parties. Two party lists collaborated in the campaign field experiment: Akbayan, Citizens' Action Party, and Umalab Ka.

Akbayan is one of the most prominent party lists nationwide and the more established of the two participants in the experiment. It has consistently won at least one seat since its founding in 1998, and has been one of the five most successful party lists, of the more than 100 registered at the national level.

Founded as a left pluralist national party, Akbayan is a multisectoral party comprising labor, peasants, urban poor, women, LGBT, and youth organizations. In the 2013 campaign, however, Akbayan's message focused heavily on women. This was because Akbayan wanted to capitalize on a recent high-profile legislative victory concerning reproductive rights, as well as on its candidate for senator, a well-known feminist activist. ${ }^{5}$ In the May 2013 election, Akbayan was able to secure around $2.9 \%$ of the popular vote at the national level, which translated into two seats in the House of Representatives.

In contrast, Umalab Ka, although formally founded in 2003, did not participate in a party-list election until 2013. This party list is composed mainly of urban poor organizations and informal sector workers (i.e., drivers, street vendors, and house servants). As a political organization, Umalab Ka has dealt in the past with issues such as the demolition of informal settlers' dwellings, discussions with government agencies about the plight of the urban poor and other peripheral issues that directly affect the lives of informal workers and other marginalized sectors in society. The primary legislative agenda of Umalab Ka includes the creation of a Magna Carta to protect workers in the informal sector. ${ }^{6}$ In the 2013 election, Umalab Ka won around $0.16 \%$ of the national vote and therefore was not able to secure any representatives in Congress.

\section{Sample Selection}

The implementation of the experiment took place in two densely populated regions in the Philippines: the National Capital Region (NCR), which comprises Manila City and its suburbs, and the neighboring Calabarzon region. The evaluation of the campaign experiment focuses on electoral returns and self-reported voting behavior from 39 randomly selected barangays of 13

\footnotetext{
${ }^{5}$ The platform and constitution of the Akbayan party list can be found at www.akbayan.org.ph.

${ }^{6}$ The entire legislative agenda of the Umalab Ka party list can be found at www.facebook.com/notes/umalab-ka-partylist.
} 
municipalities following a two-stage cluster sampling. Electoral barangays are subdivisions of municipalities equivalent to US wards and headed by barangay captains. As shown in supporting information (SI) Figure A.1 (p. 3 ), we randomly selected 7 of 17 municipalities from the NCR and 6 of 90 municipalities from Calabarzon. ${ }^{7}$ For each municipality selected in its respective region (i.e., either NCR or Calabarzon), we randomly chose three barangays and assign one of these to the treatment group and the remaining two to the control group. At this second stage, and to avoid the risk of contamination between treatment and control groups, we replaced a selected barangay and resampled another from the universe of barangays at each municipality whenever the distance between any two selected barangays was less than $1.5 \mathrm{~km}$. This procedure is repeated until no proximate barangays are selected. Finally, we randomly assigned the selected municipalities to each of the two party lists involved in the experiment.

The local nongovernmental organization, the Center for Popular Empowerment (CPE) was in charge of implementing the field experiment. It is important to note that, from the initial random selection of municipalities and barangays, the research team of $\mathrm{CPE}$ made some adjustments in the sample selection due to logistic difficulties encountered in the field while implementing the town-hall meetings. First, in the selected municipalities of Marikina and Valenzuela, the town-hall meeting organizers switched the originally selected control barangay for the treatment barangay. ${ }^{8}$ The reason behind this decision was that the incumbent officials associated with another party list (Alay Buhay) were hostile to the CPE research team and blocked the implementation of town-hall meetings in the originally selected treatment units. This issue made it impossible to organize and announce scheduled meetings before the election at other randomized selected barangays. In these cases, both party lists used their presence at the originally selected controls to organize the series of town-hall meetings. Second, in the municipality of Louisiana, the original treatment barangay, San Roque, could not be reached by the party-list Umalab Ka given the difficulties posed by the local authorities to imple-

${ }^{7}$ On average, there are 58 and 25 barangays per municipality in NCR and Calabarzon, respectively. NCR accounts for $49.54 \%$ of the population of both regions, whereas Calabarzon accounts for $51.46 \%$.

${ }^{8}$ In Marikina, town-hall meetings were implemented in the originally control unit, Barangka, instead of the selected treatment barangay Concepcion Dos. In Valenzuela, town-hall meetings were implemented in Punturin instead of the originally selected treatment barangay Isla. ment the meetings. Instead, meetings were held in the barangays of San Diego and San Antonio, chosen by the party-list representatives themselves. Given these compliance issues, all of our analyses estimate both intention-to-treat (ITT) effects, using assigned treatment rather than implemented treatment, and complier average causal effects (CACE), instrumenting treatment status with the original random assignment.

SI Tables A.1 and A.2 (p. 3) present the sample of selected barangays for each municipality and the treatment status for each participating party list.

\section{Treatment Barangays}

In advance of the implementation of town-hall meetings, one representative from $\mathrm{CPE}$ conducted a series of meetings with the party-list representatives to instruct them on the specifications of the protocol they had to follow in treatment barangays.

A team of one organizer from $\mathrm{CPE}$ along with partylist members (mainly nominees and leading officers) implemented two or three town-hall meetings, each with around 40 participants, during the period between April 21 and May 9 of election year. A staff of approximately four CPE staff members, along with party-list representatives, deployed teams a week in advance of the scheduled meetings to inform potential voters door to door and in public areas about the location, date, and time of the town-hall meetings. At the time of the implementation, every citizen who wished to attend a meeting was offered a place in the town-hall. On average, the townhall meetings lasted between 90 and 120 minutes, and were divided into three stages: introduction (10-15 minutes), deliberation (70-95 minutes), and resolution and commitment (10 minutes).

At the introduction stage, the CPE representative explained the purpose of the party-list electoral system. In general, the audience was informed of the value of electing a party-list representative as differentiated from a district representative, mainly in that its objective is to give political representation to marginalized societal sectors.

Second, the party-list representative gave an introductory speech containing its platform and programmatic statement, following as a guideline a homogenous statement previously designed by the party-list officials and transmitted to its nominees. Akbayan's representative explained the services that the party provides to its members and its legislative accomplishments. The partylist representative highlighted Akbayan's role in passing the Responsible Parenthood Law, explaining how the law would help marginalized women. At this stage, Umalab 
Ka representatives stated that, if elected, they would push for the creation of laws aimed at protecting the urban poor, such as legislation to address price stabilizations on basic commodities during natural disasters and laws to give job security to informal workers.

The deliberation stage usually consisted of several rounds of questions/comments, in which participants were encouraged to suggest amendments to the original policies presented by the party lists and to give new proposals that could potentially be included in the party-list platform. Town-hall meeting participants had no restrictions to debate the policy proposals among themselves and with the candidates. For example, at a meeting conducted by Akbayan in the barangay of San Diego, a young participant raised the concern that it was common for parties to make a lot of promises, but he wanted to know exactly what, if elected, Akbayan would do. The party representative clarified that, as members of Congress, they would be involved in crafting meaningful policies and drafting the budget. At a meeting conducted by Umalab Ka in the barangay Santo Rosario-Silangan, a woman raised the issue of land property that affected many households in that barangay. The Umalab Ka representative emphasized that one of their main objectives, if elected, was to reform the Urban Development and Housing Act to better regulate informal settling and help women like her.

At the resolution and commitment stage, the $\mathrm{CPE}$ representative summarized the main proposals of the party list and the main issues raised during deliberation. At this stage, the party-list representative made a commitment to the participants to transmit the summary report of the meeting to the party-list leaders and candidates with their suggestions and proposals.

It is worth emphasizing that in each of the town-hall meetings implemented in the treatment barangays, there was no cash or any other type of valuable gift distributed to the meeting attendees. Both party lists only distributed flyers and attached posters and banners at the meeting locations.

\section{Control Barangays}

In those barangays assigned to the control group, there were no instructions to party-list representatives on what campaign strategy to follow. The only restriction was that town-hall meetings were not to be implemented. In fact, both party lists followed a "business-as-usual" strategy implemented elsewhere.

The only relevant distinction between control "barangays" and those not selected in the randomiza- tion protocol is that in the latter, we were able to monitor the presence and campaign efforts of both party lists involved in the experiment. ${ }^{9} \mathrm{CPE}$ engaged four field researchers to monitor the campaign strategy of party lists at each control barangay. The reports from the field indicate that both parties deployed mobile propaganda teams asking people for their vote. In addition, party lists followed a door-to-door campaign in which party-list volunteers distributed flyers to households.

Finally, party lists organized rallies in control barangay to mobilize voters. The average size of these rallies usually exceeded 100 participants, notably higher than any of the town-hall meetings implemented in treatment barangays. In terms of the interaction between candidate and voters, party rallies are what we call "oneway communication" campaigns, in which only party-list leaders engaged the audience with a message containing the party's policy platform, without the possibility that attendees speak directly to the candidate.

\section{Data}

We use two types of data for the evaluation of the field experiment. To quantify the treatment effect of the presence of town-hall meetings on voting behavior, we use official data reported by COMELEC to construct barangay-level measures of turnout and vote shares. SI Tables A.1 and A.2 (p. 3) present the official information at both general and party-list elections. Figure 1 presents the number of potential voters who attended at least one town-hall meeting in treatment barangays as a proportion of both the number of registered voters and the party-list voters for the 2013 election. On average, meeting attendees accounted for $5 \%$ of potential voters and $8 \%$ of partylist voters. There is, however, a huge amount of variation in the proportion of meeting attendees across barangays. On highly populated barangays, such as Payatas and Ususan, meeting attendees accounted for barely $0.5 \%$ of party-list voters, whereas in barangays with a smaller number of voters such Barangay 738 or Lalakay, meeting attendees accounted for more than $25 \%$ of the electorate. In our estimation, we show the differential impact of town-hall meetings by the size of the electorate and then we present the heterogeneous effect of town-hall meetings as a function of the proportion of attendees.

\footnotetext{
${ }^{9}$ COMELEC does not disclose electoral returns of the party-list election at the barangay level. To obtain this information, we collected the electoral results from each polling precinct in the weeks after the election. These data would have been unfeasible to obtain for all the barangays at each municipality.
} 


\section{FIGURE 1 Proportion of Town-Hall Meetings' Attendees}
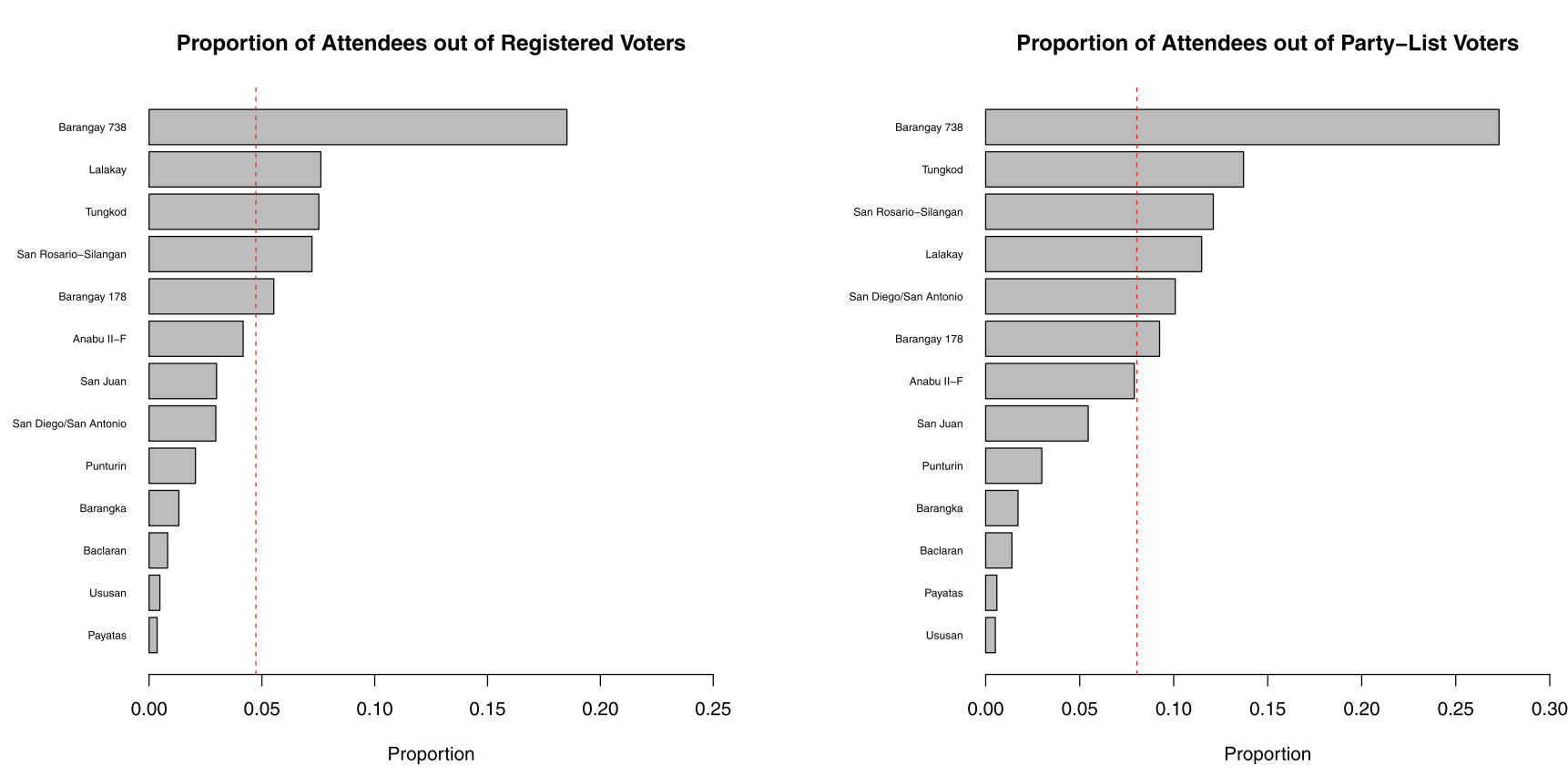

Note: The red dashed lines depict the mean attendance proportion across barangays.

To estimate differential effects of town hall meetings by voters' characteristics, as well as potential mechanisms, we analyze individual-level data for a subset of treatment and control barangays using a postelectoral survey that CPE implemented two weeks after the election. ${ }^{10}$ This survey covers standard demographic characteristics, self-reported voting behavior, town-hall meeting attendance, and political attitudes for a total of 1,314 Filipino citizens of voting age. ${ }^{11}$

For this survey, CPE followed a "random walk" and quota sampling procedure, with an intended quota of 40 respondents per barangay. In control and treatment barangays, enumerators sampled households following a "random walk" starting from the barangay's town-hall in control areas and from the location of the town-hall meetings in treatment barangays. ${ }^{12}$

\footnotetext{
${ }^{10}$ The municipalities that were excluded from the survey analysis because CPE did not sample respondents in both treatment and control barangays are Imus, Pateros, and Santa Maria.

${ }^{11}$ The effective sample that we use in the analysis is of 1,082 citizens, which excludes those respondents who did not give a valid response for the turnout question. The main individual results are qualitatively similar when we replicate them using a balanced survey data via multiple imputation (King et al. 2001) as can be seen in SI Appendix E (p. 21).

${ }^{12}$ First, the household nearest to the starting point was the first included and then the enumerators flipped a coin to decide the direction to move next. Following the chosen road or path, the protocol dictated to include every fifth household until the quota was completed.
}

Given its nonrepresentative sampling procedure, the postelectoral survey does not reflect the sociodemographic characteristics of potential voters at the barangay level. The presence of sampling biases, along with the lack of census data at the barangay level, prevents us from directly comparing the aggregate electoral returns to the individual-level survey responses. Nevertheless, the postelectoral survey is a valuable source of voters' characteristics and attitudes to assess under what conditions deliberative campaigns were more effective for delivering a political platform to voters.

\section{Barangay-Level Analysis}

We evaluate the effect of town-hall meetings (i.e., treatment) on aggregate voting behavior at the barangay level on two main electoral outcomes: party-list turnout (as a proportion of registered voters) and vote shares (as a proportion of total party-list votes), both obtained from official results provided by COMELEC.

The random assignment process of the campaign treatment makes identification of the ITT of town-hall meetings on aggregate electoral returns straightforward using the following regression of the observed electoral return $Y_{j, k}$ in barangay $j=1, \ldots, J$, within municipality $k=1, \ldots, K$, on an assignment dummy, $Z_{j, k}$, which equals 1 if either party $p \in\{$ Akbayan, Umalab Ka\} was 


\section{TABLE 1 Intention-to-Treat Effect on Electoral Returns at the Barangay Level}

\begin{tabular}{lcccc}
\hline & \multicolumn{3}{c}{ Dependent variable } \\
\cline { 2 - 5 } & Turnout & Vote (overall) & Vote (Akbayan) & Vote (Umalab Ka) \\
& $(\mathbf{1})$ & $(\mathbf{2})$ & $(\mathbf{3})$ & $\mathbf{( 4 )}$ \\
\hline ITT & -4.544 & 1.096 & 1.955 & 0.360 \\
CACE & -5.908 & 1.425 & 2.606 & 0.459 \\
& $p=.404$ & $p=.048$ & $p=.087$ & $p=.141$ \\
Control & 65.040 & 2.397 & 4.897 & 0.253 \\
& $p=.000$ & $p=.005$ & $p=.0003$ & $p=.248$ \\
City FE & Yes & Yes & Yes & Yes \\
Observations & 39 & 39 & 18 & 21 \\
$R^{2}$ & .389 & .776 & .453 & .412 \\
\hline
\end{tabular}

Note: Inference for the ITT and CACE under randomization of the treatment. Permutation $p$-values for ITT.

randomly assigned to implement a deliberative campaign in barangay $j$ and zero, otherwise

$$
Y_{j, k}=\delta_{k}+\beta Z_{j, k}+\epsilon_{j, k},
$$

where $\beta$ is our coefficient of interest, as it captures the ITT. The parameter $\delta_{k}$ captures municipality fixed effects and $\epsilon_{j, k}$ is an idiosyncratic error term.

The ITT computes the average change in electoral returns from the assignment of town-hall meetings irrespective of whether the deliberative campaigns were implemented on a small or large proportion of barangays. Beyond capturing the average effectiveness of deliberative campaigns, we are also interested in computing the CACE, which captures the effect of the implementation of town-hall meetings on voting behavior for the subpopulation of "complier" barangays. These are defined as those that were assigned to the treatment group and were actually treated. This subpopulation of interest exclude the barangays of Concepcion Dos, Isla, and San Roque, in which town-hall meetings could not be implemented as originally assigned. The CACE is estimated via instrumental variable estimation of the following equation:

$$
Y_{j k}=\lambda_{k}+\alpha T_{j, k}+v_{j k},
$$

where we instrument the implementation of town-hall meetings, $T_{j, k}$ with assignment $Z_{j, k}$. The coefficient $\alpha$ captures the CACE, $\lambda_{k}$ captures municipality fixed effects, and $v_{j k}$ is the error term.

To conduct inference, we present uncertainty estimates of the ITT and CACE under a nonparametric permutation test (Efron and Tibshirani 1994). We focus on the statistical inference under randomization or permutation resampling, as it does not rely on random sampling from a known population or on any distributional assumption of the quantity of interest, making it less sen- sitive to the small number of sampled barangays. We compute the distribution for the null hypothesis of no effect from the assignment of town-hall meetings for all barangays and calculate a $p$-value for any withinmunicipality permutation of the treatment assignment that we might have observed in the experiment. SI Appendix B (p. 4) shows evidence that the randomization of town-hall meetings successfully achieved balance across treatment and control barangays given the available pretreatment official statistics.

\section{Effect of Town-Hall Meetings on Electoral Returns}

We present the estimates of the ITT and CACE for turnout and vote shares across barangays in Table $1 .{ }^{13}$ First, looking at the results on party-list turnout, we can see that the presence of town-hall meetings does not have a significant effect on voter turnout in the party-list race. However, conditional on casting a ballot, the presence of town-hall meetings has a positive and statistically significant effect ( $p$-value $<.05)$ on aggregate vote shares when we pool both party lists together. These results suggest that the vote shares in barangays assigned to deliberative campaigns increase $1.1 \%$ with respect to the baseline of $2.4 \%$ obtained by "one-way" communication campaigns. This result translates into an overall electoral return of the assignment of deliberative campaigns of approximately $46 \%$. Given the estimated CACE, we find that the effect of implementation of town-hall meetings on vote shares among "complier" barangays is $1.43 \%$ or

\footnotetext{
${ }^{13}$ SI Figure C.1 (p. 9) presents these results graphically with respect to their empirical null distribution.
} 


\section{FIGURE 2 Heterogeneous Effects of Town-Hall Meetings by Size of the Electorate and Proportion of Meeting Attendees}
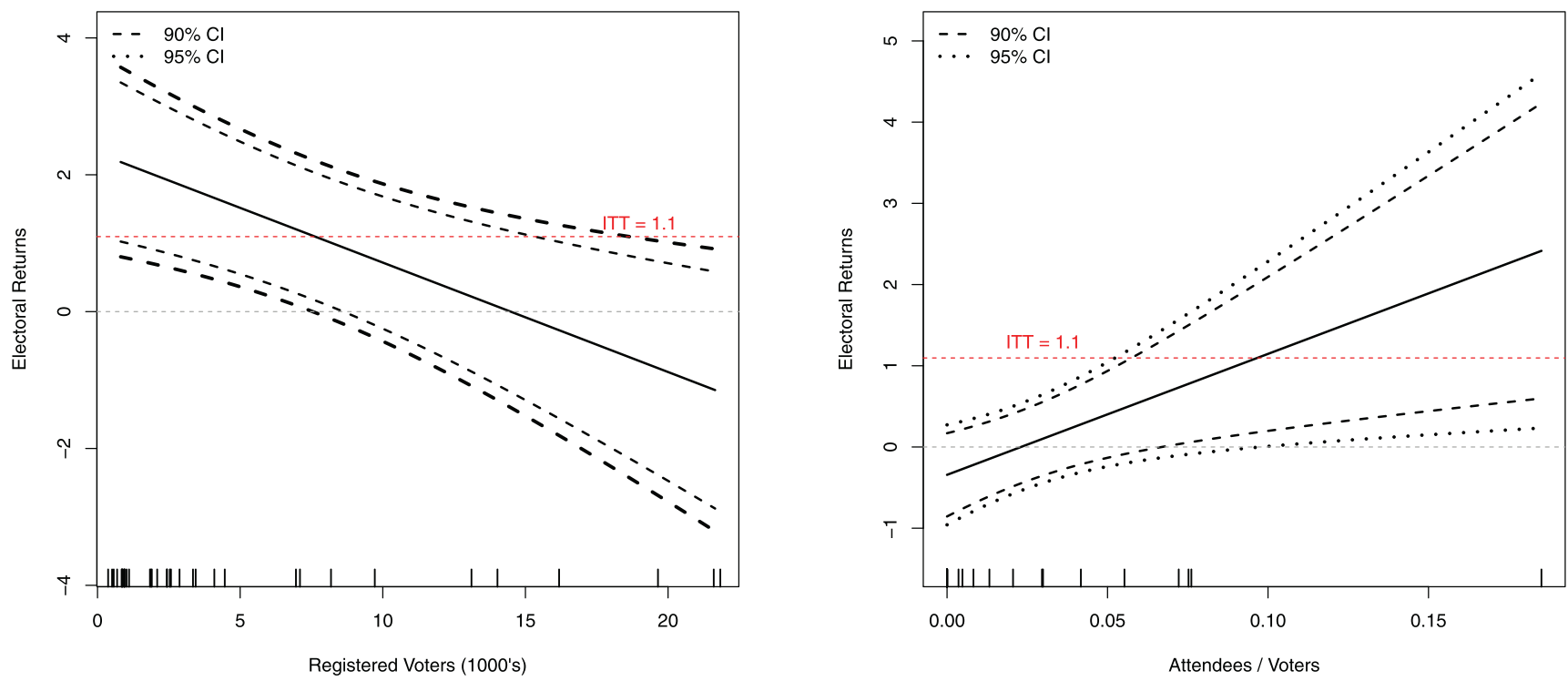

Note: The left panel plots the marginal effect of town-hall meetings on vote shares conditional on the number of registered voters per barangay. The right panel shows the marginal effect of town-hall meetings on vote shares conditional on the proportion of town-hall meeting attendees per barangay.

$60 \%$ in terms of electoral returns with respect to the control group.

When we split the sample by treatment party list, we find that both treatment effects are positive, but the ITT is statistically significant only for Akbayan ( $p$-value <.1). In particular, Akbayan was rewarded, on average, with a $1.96 \%$ higher vote share in treatment barangays. Umalab $\mathrm{Ka}$, in turn, obtained an increase in $0.36 \%$ vote share in those barangays where town-hall meetings were implemented, which represents approximately 1.4 times their vote in control barangays. These results are not only considerable in magnitude with respect to baseline scenarios but also politically meaningful. In the case of Akbayan, this estimated return, if extrapolated at the national level, would directly translate into an additional seat in Congress, which Akbayan failed to secure in the 2013 election. Moreover, the CACE by party list represents electoral returns with respect to "business-asusual" campaigns of $53 \%$ and $181 \%$, for Akbayan and Umalab Ka , respectively. Roughly, these estimated effects imply that town-hall meeting attendees are, on average, 13.7 percentage points more likely to vote for the party list than nonattendees. ${ }^{14}$ Although this increase in voting probability is not causally identified, given nonrandom

\footnotetext{
${ }^{14}$ This is estimated from the ratio of the estimated ITT (i.e., 1.1\% for aggregate vote shares) to the proportion of town-hall meeting attendees (i.e., $8 \%$ of party-list voters).
}

selection of voters into meetings, it is another measure of the effectiveness associated with deliberative campaigns.

The previous average estimates, albeit informative of the aggregate effect of town-hall meetings on electoral returns, do not allow us to account for the observed variation in treatment intensity. As we have shown in Figure 1 , there is significant differences across barangays in the proportion of voters who were exposed to the presence of town-hall meetings, which affects the impact of deliberative campaigns on aggregate voting behavior. To address this issue, we first estimate heterogeneous effects of town-hall meetings by the size of the electorate. We estimate a linear interaction between treatment assignment and the number of registered voters, while controlling for municipality fixed effects. The left panel of Figure 2 shows these marginal ITT on vote shares (pooling both party lists together). As can be seen, the largest effect of deliberative campaigns is estimated on the smallest barangays (by the number of registered voters), in which the exposure to town-hall meetings is potentially the largest. For instance, the effect of town-hall meetings on a small barangay such as Tungkod, with less than 1,000 registered voters, is approximately $2.2 \%$. This effect represents twice the estimated ITT across barangays. Moreover, once a barangay exceeds 7,500 voters, the ITT is not statistically different from zero.

Second, we estimate the change in aggregate vote shares as a function of the proportion of treated voters 
(after controlling for municipality fixed effects). Because the proportion of meeting attendees per barangay is not randomly assigned, we use assignment of town-hall meetings as an instrument. The right panel Figure 2 summarizes the effects of the proportion of attendees on vote shares. As can be seen, electoral returns significantly increase with the proportion of town-hall meeting attendees. Pooling both party lists together, we find that an increase in $5 \%$ of meeting attendees, equivalent to an s.d. in attendance in those barangays assigned to treatment, is related to an increase in 1.29 percentage points in vote share. The evidence that town-hall meetings are more effective as the proportion of voters treated increases is reassuring and allows us to capture more subtle effects of deliberative campaigns across parties. In the case of Akbayan, the effect of town-hall meetings is statistically similar to the average ITT only for barangays with an attendance greater than $5 \%$ of registered voters. For Umalab $\mathrm{Ka}$, although the average ITT across barangays is not statistically different from zero, an increase in attendance of $2.6 \%$ (the s.d. in the data) is associated with a significant increase in vote share of $0.31 \% .^{15}$

\section{Individual-Level Analysis}

To estimate heterogeneity in causal effects across different subsets of respondents and provide some evidence on the causal mechanisms behind aggregate voting behavior, we use the postelectoral survey that contains turnout and vote declarations, as well as political and sociodemographic characteristics in treatment and control barangays. ${ }^{16}$ SI Appendix B (p. 4) tests for the presence of pretreatment covariate imbalance, whereas SI Appendix D (p. 15) shows that the individual-level results are robust to controlling for the set of pretreatment covariates contained in the individual survey.

Analogous to the aggregate analysis, we use the postelectoral survey to estimate the identified ITT and CACE, as well as heterogeneous effects by respondents' characteristics. ${ }^{17}$ Let $i=1, \ldots, N$ denote a voter in barangay $j$

\footnotetext{
${ }^{15}$ SI Figure C.2 (p. 14) shows heterogeneous effects by party list.

${ }^{16}$ The survey questions used to generate all the individual-level outcomes can be found in SI Appendix H (p. 26).

${ }^{17}$ Although we observe meeting attendance in the survey data, this is not randomly assigned and could be affected by both observed and unobserved characteristics not accounted in the randomization protocol. SI Appendix G (p. 25) shows that meeting attendees are significantly different, with respect to pretreatment covariates and their sources of political information, to both nonattendees in treatment barangays and attendees to rallies in the control group.
}

within municipality $k$. Analogous to Equation (1) for the aggregate effect, the ITT effect with individual data can be identified with the following regression:

$$
Y_{i, j, k}=\delta_{k}^{\text {survey }}+\beta^{\text {survey }} Z_{j, k}+\epsilon_{i, j, k}^{\text {survey }},
$$

where $\beta^{\text {survey }}$ captures the individual-level ITT, $\delta_{k}^{\text {survey }}$ captures municipality fixed effects and $\epsilon_{i, j, k}^{\text {survey }}$ is the error term clustered at the barangay level, which is the level of treatment assignment. Similarly, we can estimate the effect of town-hall meeting implementation on those barangays that implemented the assigned treatment with an IV regression analogous to Equation (2):

$$
Y_{i, j, k}=\lambda_{k}^{\text {survey }}+\alpha_{j k}^{\text {survey }} T_{j, k}+v_{i, j, k}^{\text {survey }},
$$

where $\alpha^{\text {survey }}$ captures the individual-level CACE and $Z_{j, k}$ instruments for $T_{j, k}$.

All of the individual effects adjust for the oversampling of meeting attendees via inverse probability weighting, where the adjustment in treatment barangays is given by the proportion of (self-reported) survey attendees to actual barangay attendees, obtained from townhall meetings' attendance sheets. As a robustness check, SI Appendix F (p. 22) presents the unadjusted individual results, which overrepresent self-reported attendees. As with the aggregate data, inference of the unweighted results is done under a nonparametric permutation test that uses the two-stage cluster randomization design to estimate empirical $p$-values for the ITT effects.

\section{Effect of Town-Hall Meetings on Individual Behavior}

Figure 3 presents the ITT and CACE with the individuallevel data. ${ }^{18}$ Although absolute magnitudes of treatment effects are not comparable between official and survey data, we can see that, consistent with the aggregate results, the individual propensity to turn out to vote is not significantly affected by the presence of deliberative campaigns. In contrast, the presence of town-hall meetings affects overall vote choice positively, increasing the probability of voting for the party under the deliberative campaign approximately $13.5 \%$ with respect to the control group. When we split the results by party, we find, as with the aggregate data, that the average electoral returns of town-hall meetings are statistically significant only for Akbayan. The probability of voting for this party in treatment barangays is approximately $16.7 \%$ higher than in the control group. In the survey, the propensity to vote for Umalab Ka increases 6.6\% in barangays where parties

\footnotetext{
${ }^{18}$ SI Table C.2 (p. 10) shows these point estimates with their asso-
} ciated $p$-values. 


\section{FIGURE 3 Effect of Town-Hall Meetings on Individual-Level Vote Choice Using Survey Data}

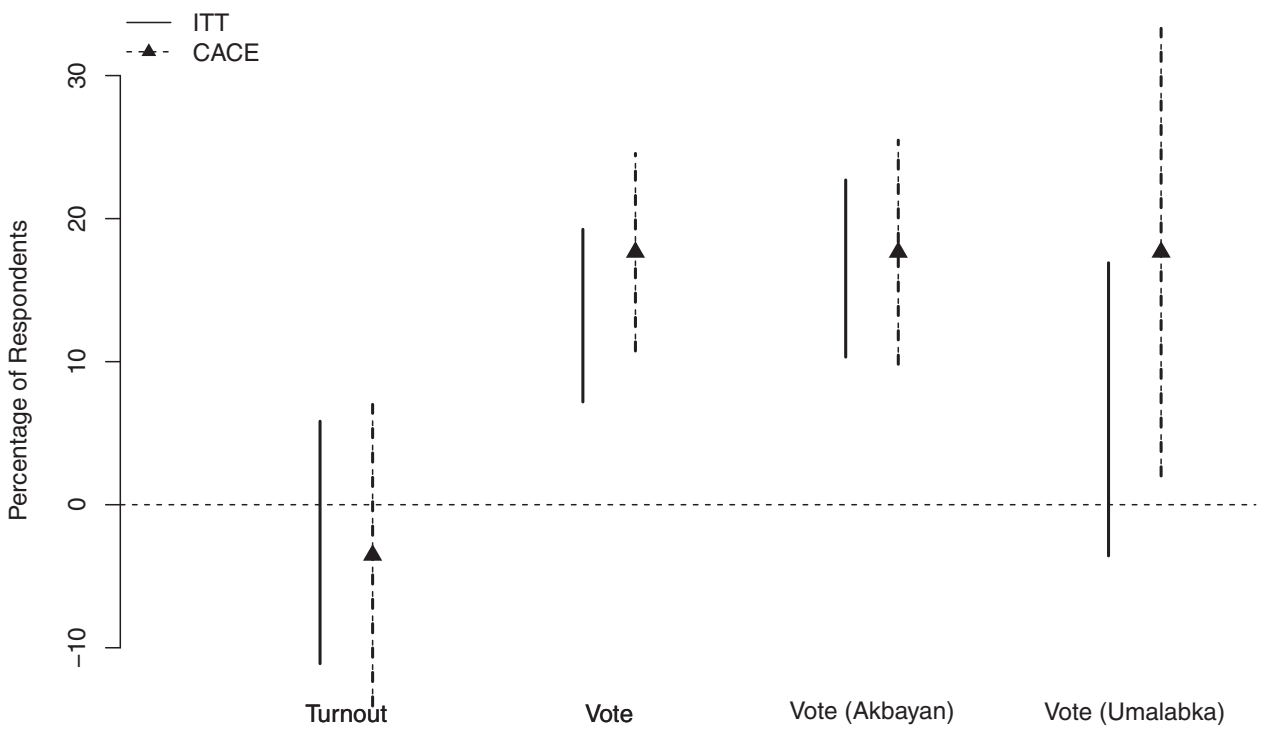

Note: Lines represent 95\% confidence intervals. All estimates are based on a linear probability model with city fixed effects and clustered standard errors at the barangay level.

implemented town-hall meetings with respect to "oneway" communication campaigns (although the ITT does not reach statistical significance). In contrast, the CACE on the probability of voting for both participating parties is statistically significant and similar in magnitude, with an effect of town-hall meeting implementation on voting probability of approximately $17.7 \%$.

\section{Heterogeneous Effects by Income, Education, and Gender}

By fixing the platform's content that parties delivered in treatment and control barangays, we are able to assess the effectiveness of deliberation conditional on a particular campaign message. This feature of the experiment allows us to test differential effects of town-hall meetings for the subset of voters at whom the campaign platforms is aimed at.

First, we assess whether there is a differential effect of town-hall meetings on informal sector workers and the urban poor, for which Umalab Ka's platform was designed. Although the postelectoral survey did not ask respondents to provide information on their employment status, we use their self-reported level of income and education as a crude proxy for informality. ${ }^{19}$

\footnotetext{
${ }^{19}$ For this, we rely on the labor economics literature, which has consistently found that in developing countries, such as the Philip-
}

Second, we condition the effect of town-hall meetings on respondents' gender to test whether the effect of the deliberative strategy is different for women who are the primary focus of Akbayan's platform, as it primarily emphasized women's rights in the labor market.

To obtain a differential ITT effect of town-hall meetings, we estimate an interaction model of the form

$$
\begin{aligned}
Y_{i, j, k}= & \gamma_{k}^{\text {survey }}+\beta_{1}^{\text {survey }} Z_{j, k}+\beta_{2}^{\text {survey }} X_{i, j, k} \\
& +\beta_{3}^{\text {survey }}\left(Z_{j, k} \times X_{i, j, k}\right)+\xi_{i, j, k},
\end{aligned}
$$

where $X_{i, j, k}$ denotes the pretreatment conditioning variable (either income, education, or gender). ${ }^{20}$ The parameter $\gamma_{k}^{\text {survey }}$ captures municipality fixed effects and $\xi_{i, j, k}$ is an idiosyncratic error term clustered at the barangay level.

We also estimate a differential CACE, with a similar specification to Equation (5) but instrumenting treatment status with treatment assignment at the barangay level.

Figure 4 graphically depicts the marginal effects of town-hall meetings conditioned by income, education, and gender, along with $95 \%$ confidence intervals. In the upper panel, we present the differential effects on

pines, workers employed in the untaxed, unregulated sector, tend to have lower income and less education than their counterparts in the formal sector (Amaral and Quintin 2006; Maloney 1999).

${ }^{20}$ SI Appendix D (p. 15) shows that estimates from Equation (5) are robust to adding additional pretreatment covariates. 
FIGURE 4 Marginal Effect of Town-Hall Meetings on Outcomes by Income, Gender, and Education
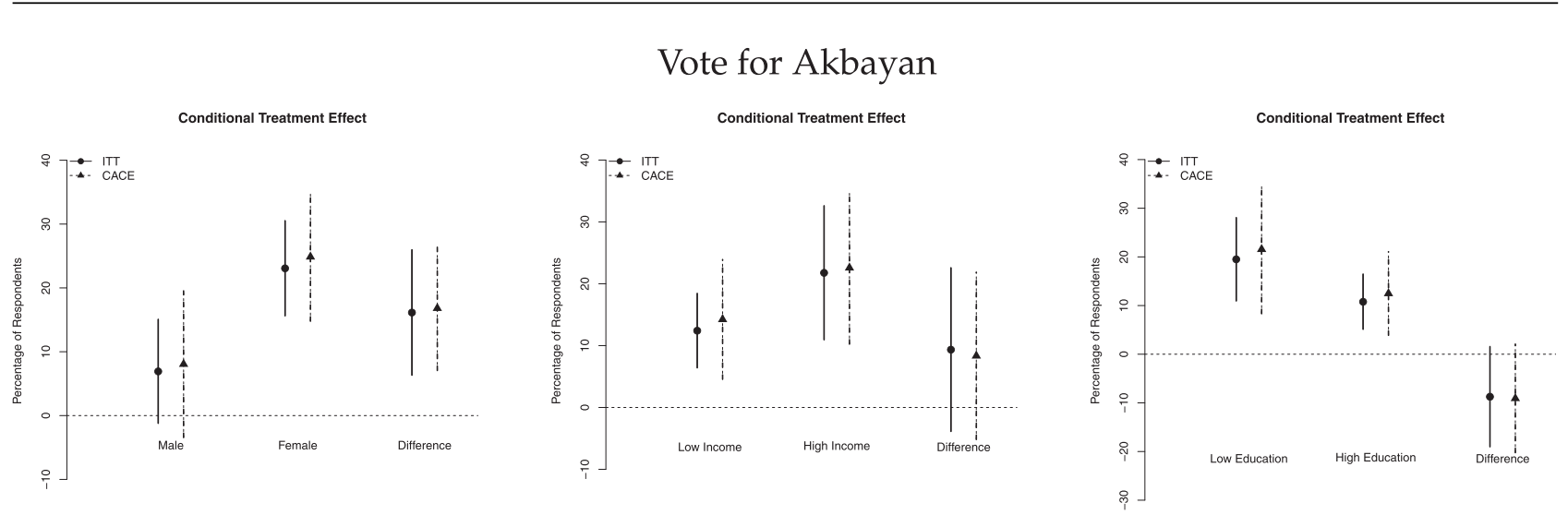

Vote for Umalab Ka
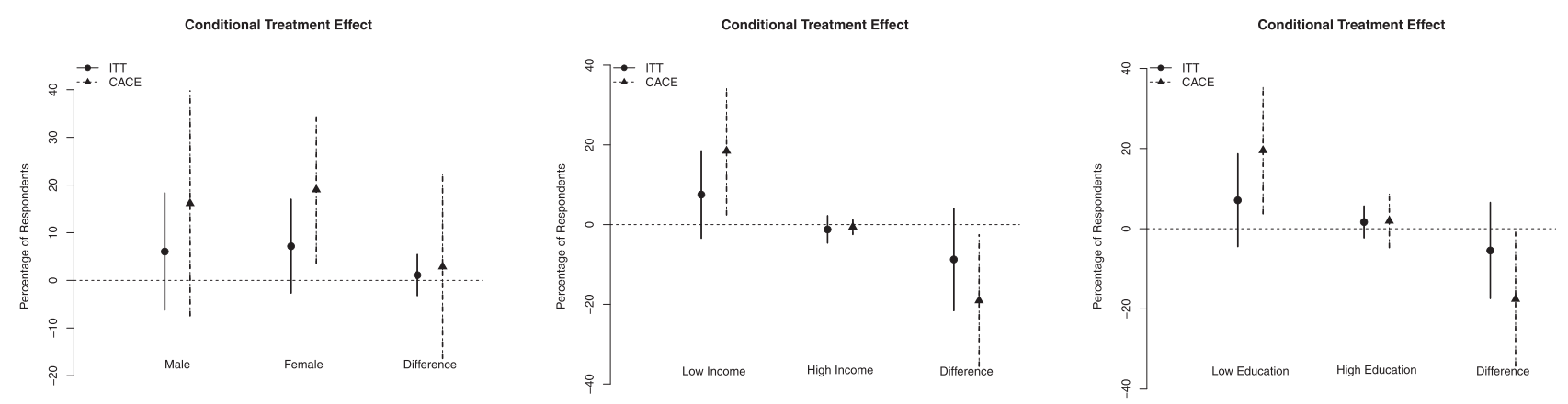

Effect by Gender

Effect by Income

Effect by Education

Note: Lines represent 95\% confidence intervals. All estimates are based on a linear probability model with city fixed effects and clustered standard errors at the barangay level.

Akbayan returns. Consistent with Akbayan's policy platform, the positive impact of deliberative campaigns on electoral returns is driven exclusively by women, as both ITT and CACE are positive only among female voters. On average, women are $25 \%$ more likely to vote for Akbayan when their platform is delivered in town-hall meetings than through "one-way" communication campaigns. We find no statistically significant differences by income on the effect of town-hall meetings on electoral returns. Nonetheless, less educated voters in our sample seem to be $9 \%$ more likely, compared to respondents with higher education, to vote for Akbayan's platform under a deliberative campaign, although this effect is only statistically significant at the $10 \%$ level.

The lower panel of Figure 4 shows the differential impact of town-hall meetings on Umalab Ka electoral returns. As with the estimated average effects shown in Figure 3, differences by voter characteristics are not statistically significant when we focus on treatment assignment (i.e., ITT). However, when we estimate the CACE, we find heterogenous effects by income and education consistent with the policy platform of Umalab $\mathrm{Ka}$, which focused on the demands of the urban poor. In particular, town-hall meetings implemented by Umalab $\mathrm{Ka}$ increased the probability of voting for that party by $18.5 \%$ among low income voters, whereas this effect is not statistically different from zero for survey respondents with an income larger than 10,000 pesos. Similarly, the effect of the presence of town-hall meetings on the probability of voting for Umalabka is $19.5 \%$ for respondents with as much as primary education, whereas the presence of town-hall meetings does not have a statistical significant effect on the propensity to vote for Umalab Ka among respondents with a high school diploma or more. Finally, we find no differential treatment effect by gender on Umalab Ka electoral returns. 
Overall, the conditional effects of town-hall meetings are consistent with the fact that the main recipients of the proposed policies contained in the party-list platforms, namely women and the urban poor, directly rewarded the party lists to a larger extent when these platforms were delivered through a deliberative campaign. As the platform content is the same across treatment conditions, these results imply that the consequences of programmatic policies are better understood when voters debate with candidates compared to the scenario in which voters just listen passively to the politician's message. More importantly, voters respond to this information and change their vote according to their own policy priorities.

\section{Causal Mechanisms: The Effect of Town-Hall Meetings on Attitudes about Gender Discrimination and Poverty}

Having found differential effects of deliberative campaigns on voting behavior for the main beneficiaries of party lists' platforms, we turn to explore whether townhall meetings are more effective in changing voters' attitudes regarding the core policies emphasized by both party lists in the experiment. For Akbayan, we compute attitudinal differences on issues related to gender discrimination and sexism. In this way, we assess whether Akbayan's message induces a higher awareness of gender inequality and gender discrimination when platforms are transmitted in town-hall meetings versus "one-way" communication devices. In the case of Umalab Ka, we compute the ITT and CACE on voters' attitudes about poverty and income inequality, which were the main priorities of its policy platform.

Voters' attitudes on gender discrimination and sexism are constructed from all six survey questions in which respondents were asked to show their degree of agreement or disagreement with respect to statements involving gender differences in the quality of House Representatives (Female Rep.), female representation in politics (Female Pol.), gender equality (Equality), gender discrimination in the labor market (Discrimination), and sexual harassment toward women (Harassment). ${ }^{21}$

To measure voters' attitudes on issues emphasized by Umalab Ka in their platform, we use all four survey questions that ask voters about the relevance of issues such as poverty (Poverty), the income gap between the rich and poor (GAP), a poverty-reducing policy (CCT),

\footnotetext{
${ }^{21}$ The six statements used to generate gender-related attitudinal variables can be found in SI Appendix H (p. 28).
}

and corruption and graft (Corruption). For poverty, income gap, and corruption and graft, the survey captures how intensely voters agree with the statement that each of these issues is one of the Philippines' most important problems. For the poverty-reducing policy, the survey asks to rank the policy they would like to be implemented the most among a conditional cash transfer program, an anti-corruption policy or an increase in public investment. $^{22}$

Causal effects are estimated following Anderson (2008). First, we orient each individual outcome, so that the positive direction implies more agreement. Next, we demean all outcomes and standardize them with respect to the control group mean and s.d. to use a comparable scale. Because we have multiple measures for each issue, we construct summary indices in the form of standardized inverse covariance weighted averages of the outcomes. These indices estimate an optimal linear combination of the individual measures to reflect a common latent factor. By pooling several measures of an issue into a single index, these indices are robust to overtesting; they also test for whether an issue has a "general effect"; and finally, they have more statistical power than individual-level tests.

Figure 5 presents the results regarding the effects of town-hall meetings on voter attitudes split by party list and policy issue. We present both ITT and CACE estimates with 95\% confidence intervals. The upper panel presents the results for Akbayan municipalities. Consistent with the party's platform, we show significant effects of town-hall meetings on voters' attitudes toward gender discrimination and sexism. Based on the evidence of the summary index, the presence of town-hall meetings increases awareness on gender-related issues by 0.45 s.d. units. This attitudinal change on gender-related issues is mainly driven by a positive and significant increment in two individual components: female representation in politics (by 0.49 s.d. units) and discrimination toward women (by 0.88 s.d. units). The effect of town-hall meeting implementation on gender discrimination issues is significantly larger, with a CACE on the summary index of 0.67 s.d. units. ${ }^{23}$ Moreover, voters' disagreement toward poverty-related issues also increases significantly when Akbayan implements townhall meetings compared to control areas, as can be seen in the upper-right panel of Figure 5. This significant effect is present even when the policy platform of Akbayan

\footnotetext{
${ }^{22}$ SI Appendix H (p. 29) shows the questions used to extract the poverty-related attitudinal variables.

${ }^{23}$ SI Table D.3 (p. 17) presents the point estimates and $p$-values for the overall index and each of its components.
} 


\section{FIGURE 5 ITT Effects and CACE of Attitudes on Gender Discrimination and Poverty}

Vote for Akbayan
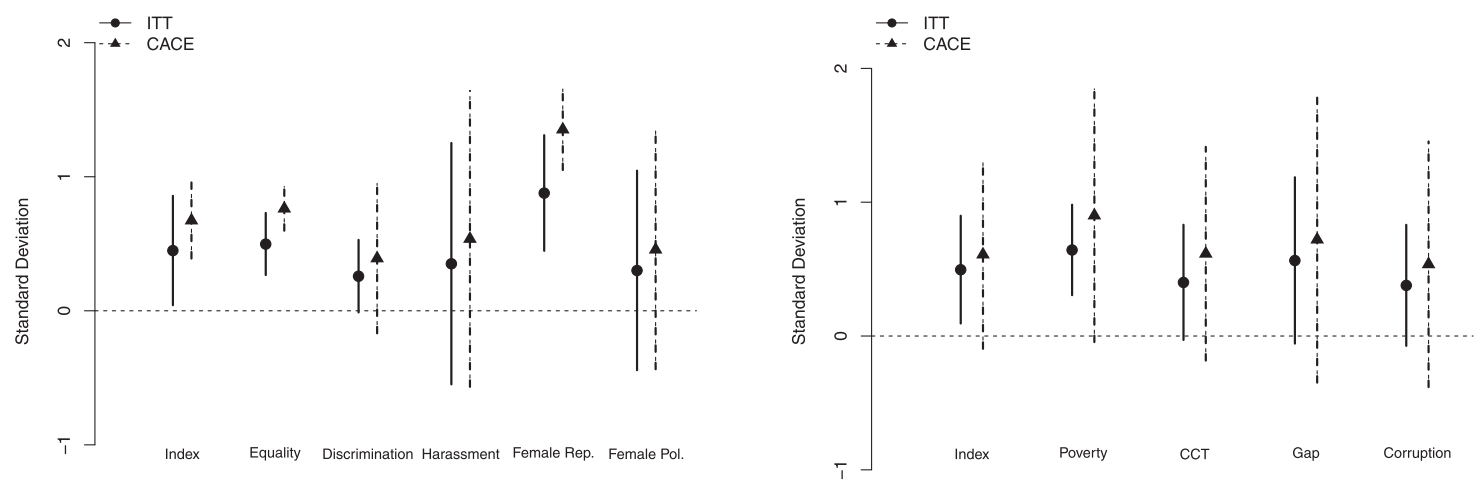

Vote for Umalab Ka

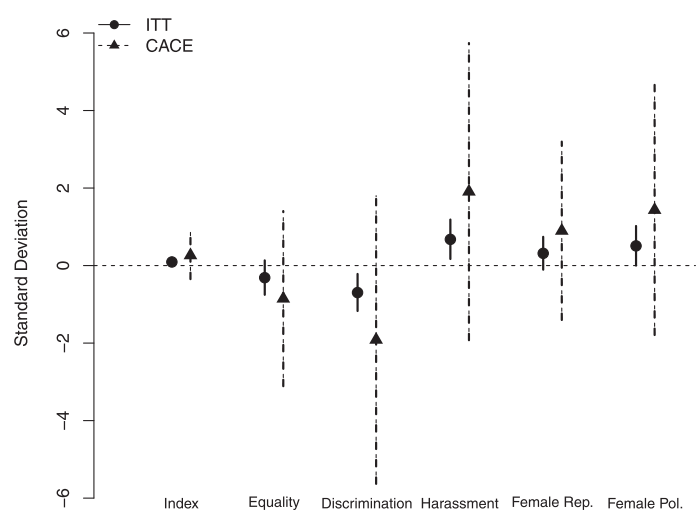

Gender Discrimination

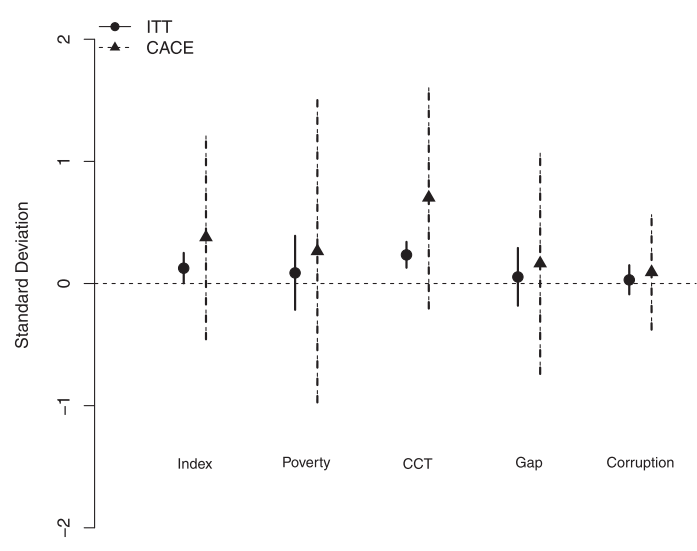

Poverty and Income Inequality

Note: Lines represent $95 \%$ confidence intervals. All estimates are based on a linear probability model with city fixed effects and clustered standard errors at the barangay level.

relegated poverty to a second-order issue, and instead, stressed women empowerment and gender equality as their main messages.

In the lower panel of Figure 5, we show the results for Umalab Ka municipalities. We find a small, but significant ITT of town-hall meetings on the general index of poverty-related attitudes ( 0.13 s.d. units), which is driven mainly by voters' preferences over a CCT program $(0.24$ s.d. units). The CACE of the general index and its com- ponents are positive, but statistically insignificant. When we look at differential gender attitudes by treatment status, we cannot reject a null effect of town hall meetings on the summary index.

The significant effect of town-hall meetings on attitudes related to gender discrimination, and to a smaller extent poverty, provides evidence that deliberative campaigns can be a more effective communication strategy in improving voters' knowledge and changing voters' beliefs 
on issues central to the party's platform. ${ }^{24}$ These general attitudinal effects, however, increase the votes only of female and poor voters who represent the direct beneficiaries of the party-list platform.

\section{Conclusion}

In this article, we present deliberative campaigns as a communication strategy that can be both electorally effective for self-interested politicians and successful in increasing voters' knowledge regarding relevant policy issues. The creation of deliberative spaces where citizens and political elites participate in meaningful conversations with real policy consequences is central to strengthen the quality of weak democracies such as the Philippines (Curato 2015; Dressel 2011; Querubin 2012). Hence, the impact of deliberative forums, such as the one presented in this article, adds to the existing arguments in favor of institutions that encourage the active engagement of citizens in the decision-making process.

The positive electoral returns of deliberative campaigns found in this article are estimated conditional on the observed strategies of the remaining parties that did not participate in the experiment. The general equilibrium effects allowing other parties to respond to this strategy are outside the scope of this article. However, even if other parties were to optimally adopt town-hall meetings, potentially diminishing their positive electoral benefits, their presence would still be a more effective strategy to deliver a policy platform to voters with respect to "one-way" communication strategies, generating a more informed political environment. Moreover, in weak democratic contexts, such as the one studied in this article, in which "business-as-usual" campaigns involve the distribution of cash and other clientelistic goods, as well as a multiarm campaign requiring canvassers and rally organizers, town-hall meetings appear to be a costeffective campaign alternative.

A future avenue of fruitful research would be to disentangle the effects of town-hall meetings on attendees from the spillover effects to untreated voters. This would require carefully tracing meeting attendees' social networks and the channels through which information is shared across voters.

\section{References}

Amaral, Pedro S., and Erwan Quintin. 2006. "A Competitive Model of the Informal Sector." Journal of Monetary Economics 53(7): 1541-53.

\footnotetext{
${ }^{24}$ We do not find heterogeneous effects by gender and income on
} these attitudinal variables.
Anderson, Michael L. 2008. "Multiple Inference and Gender Differences in the Effects of Early Intervention: A Reevaluation of the Abecedarian, Perry Preschool, and Early Training Projects." Journal of the American statistical Association 103(484): 1481-95.

Austen-Smith, David, and Timothy J. Feddersen. 2006. "Deliberation, Preference Uncertainty, and Voting Rules.” American Political Science Review 100(2): 209-17.

Ban, Radu, Saumitra Jha, and Vijayendra Rao. 2012. "Who Has Voice in a Deliberative Democracy? Evidence from Transcripts of Village Parliaments in South India." Journal of Development Economics 99(2): 428-38.

Barabas, Jason. 2004. "How Deliberation Affects Policy Opinions.” American Political Science Review 98(4): 687-701.

Casey, Katherine, Kelly Glennester, and Kelly Bidwell. 2015. "Debates: The Impact of Voter Knowledge Initiatives in Sierra Leone." https://www.sfcg.org/wp-content/uploads/ 2015/04/Impact-of-Voter-knowledge-Initiatives-in-SierraLeone.pdf

Collier, Paul, and Pedro C. Vicente. 2014. "Votes and Violence: Evidence from a Field Experiment in Nigeria." The Economic Journal 124(574): F327-55.

Coughlan, Peter J. 2000. "In Defense of Unanimous Jury Verdicts: Mistrials, Communication, and Strategic Voting." American Political Science Review 94(2): 375-93.

Curato, Nicole. 2015. "Deliberative Capacity as an Indicator of Democratic Quality: The Case of the Philippines." International Political Science Review 36(1): 99-116.

Dal Bó, Pedro, Andrew Foster, and Louis Putterman. 2010. "Institutions and Behavior: Experimental Evidence on the Effects of Democracy." The American Economic Review 100(5): 2205-29.

Dewan, Torun, Macartan Humphreys, and Daniel Rubenson. 2014. "The Elements of Political Persuasion: Content, Charisma and Cue.” The Economic Journal 124(574): F25792.

Dressel, Björn. 2011. "The Philippines: How Much Real Democracy?" International Political Science Review 32(5): 529-45.

Efron, Bradley, and Robert J. Tibshirani. 1994. An Introduction to the Bootstrap, Vol. 57. Boca Raton, FL: CRC Press.

Esterling, Kevin M., Michael A. Neblo, and David M.J. Lazer. 2011. "Means, Motive, and Opportunity in Becoming Informed about Politics a Deliberative Field Experiment with Members of Congress and Their Constituents." Public Opinion Quarterly 75(3): 483-503.

Fujiwara, Thomas, and Leonard Wantchekon. 2013. "Can Informed Public Deliberation Overcome Clientelism? Experimental Evidence from Benin." American Economic Journal: Applied Economics 5(4): 241-55.

Gerber, Alan S., and Donald P. Green. 2000. "The Effects of Canvassing, Telephone Calls, and Direct Mail on Voter Turnout: A Field Experiment." American Political Science Review 94(3): 653-63.

Goeree, Jacob K., and Leeat Yariv. 2011. "An Experimental Study of Collective Deliberation.” Econometrica 79(3): 893921.

Green, Donald P., Alan S., Gerber, and David W. Nickerson. 2003. "Getting Out the Vote in Local Elections: Results from 
Six Door-to-Door Canvassing Experiments." Journal of Politics 65(4): 1083-96.

Gutmann, Amy, and Dennis Frank Thompson. 1996. Democracy and Disagreement. Cambridge, MA: Harvard University Press.

Habermas, Jurgen. 1996. Between Facts and Norms: Contributions to a Discourse Theory of Law and Democracy. Cambridge, MA: MIT Press.

Hicken, Allen, Stephen Leider, Nico Ravanilla, and Dean Yang. 2014. "Temptation in Vote-Selling: Evidence from a Filed Experiment in the Philippines." CESifo Working Paper 4828. Munich: Center for Economic Studies.

Karpowitz, Christopher F., and Tali Mendelberg. 2014. The Silent Sex: Gender, Deliberation, and Institutions. Princeton, NJ: Princeton University Press.

Kendall, Chad, Tommaso Nannicini, and Francesco Trebbi. 2015. "How Do Voters Respond to Information? Evidence from a Randomized Campaign." American Economic Review 105(1): 322-53.

King, Gary, James Honaker, Anne Joseph, and Kenneth Scheve. 2001. "Analyzing Incomplete Political Science Data: An Alternative Algorithm for Multiple Imputation." American Political Science Review 95(1): 49-69.

Macedo, Stephen. 2010. "Why Public Reason? Citizens Reasons and the Constitution of the Public Sphere." Unpublished Manuscript . https://ssrn.com/abstract=1664085

Maloney, William F. 1999. “Does Informality Imply Segmentation in Urban Labor Markets? Evidence from Sectoral Tran- sitions in Mexico." The World Bank Economic Review 13(2): 275-302.

Meirowitz, Adam. 2006. "Designing Institutions to Aggregate Preferences and Information." Quarterly Journal of Political Science 1(4): 373-92.

Querubin, Pablo. 2012. "Political Reform and Elite Persistence: Term Limits and Political Dynasties in the Philippines." Unpublished Manuscript. https://ssrn.com/abstract=2108036

\section{Supporting Information}

Additional supporting information may be found online in the Supporting Information section at the end of the article.

Appendix A: Sample Selection

Appendix B: Balance in Aggregate and Individual Data

Appendix C: Additional Tables and Figures

Appendix D: ITT Effects with Pre-Treatment Covariates

Appendix E: ITT Effects with Balanced Panel

Appendix F: ITT Effects (Unweighted Results)

Appendix G: Correlates of Attendance

Appendix H: Survey Questions Used in the IndividualLevel Analysis 